\section{Intertemporal Choices: The Role of Feedback Frequency and Reward Timing}

\author{
Andson Braga de Aguiar' \\ ${ }^{1}$ University of Sao Paulo, School of Economics, Business Administration, and Ac- \\ countancy, Department of Accounting and Actuarial Sciences, Sao Paulo-SP, Brazil \\ José Carlos Tiomatsu Oyadomari² \\ ${ }^{2}$ Mackenzie Presbiterian University and Insper, Sao Paulo-SP, Brazil \\ Cláudio Soerger Zaro ${ }^{3}$ \\ ${ }^{3}$ State University of Mato Grosso do Sul, Accounting, Ponta Porã-MS, Brazil
}

\begin{abstract}
Purpose: We examine whether managers allocate longer-term effort when they receive quarterly than either up to a month or longer than quarterly feedback. We also examine whether reward timing moderates the relationship between feedback frequency and intertemporal choices.

Design/methodology/approach: We collect survey data from 78 middle-level managers working at a Brazilian company.

Findings: The results indicate that managers place more weight on longer-term tasks when they receive quarterly feedback. Our results also indicate that reward timing moderates the relationship between feedback frequency and intertemporal choices.
\end{abstract}

Originality/value: The contribution of this study is twofold. First, we provide empirical evidence showing the effect of feedback frequency in a setting in which feedback is not mandatory, is provided for internal purposes, and there is no capital market pressure. Second, we disentangle these two components and offer empirical evidence on the relation between feedback frequency and intertemporal choices and on the moderate role of reward timing in this relationship.

Keywords - Decision making; Feedback frequency; Reward timing; Intertemporal choice
Received on

08/03/2017

Approved on

09/05/2018

Responsible editor:

Profa. Dra. Gina Gaio Santos

Evaluation process:

Double Blind Review

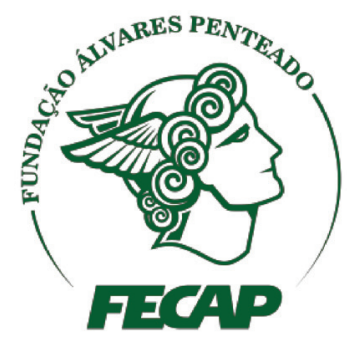

Review of Business Management 


\section{Introduction}

Performance management typically demands a significant amount of time from financial executives (Agrawal, Dinneen, \& Seth, 2016). The time dedicated to performance management includes measuring and evaluating employees' performance as well as providing feedback that drives employees' behavior to the achievement of both short- and long-term goals (Malmi \& Brown, 2008; Merchant \& Van der Stede, 2012). In particular, when designing performance management systems, one aspect that organizations should recognize is that, on one side, different levels of each of the performance management system components may have different effects on how employees allocate their time between the short- and the long-term tasks, that is, their intertemporal choices; and, on the other side, the effect of each of the performance management system components may depend on the level of other components (e.g., Chenhall, 2003; Malmi \& Brown, 2008; Otley, 1980).

The literature in management and accounting emphasizes the importance of understanding what explains intertemporal choices in an organizational context. In this respect, Laverty (1996) presents a framework in which he identifies three different levels of factors to explain managerial intertemporal choices: organizational, individual, and economic. In an empirical investigation based on Laverty's framework, Marginson and McAulay (2008) suggest that the understanding of managerial short time orientation may consider not only the economic dimension (capital market pressure and performance management systems), but also the individual (e.g. cognitive processes) and organizational dimensions. Yet most empirical evidence on managerial intertemporal choices focus on economic factors; in particular, the impact of performance management system design choices, such as: (i) different performance measures (e.g., Abernethy, Bouwens, \& Lent, 2013; Aguiar, Pinheiro, \& Oyadomari, 2014; Farrel, Kadous, \& Towry, 2008), and (ii) different types of rewards (e.g., Matta \& Beamish, 2008; Souder \& Shaver, 2010).

In this paper, we investigate the role of two components of the performance management system embedded in the individual dimension. Performance management systems are formal systems useful for providing information that influence decision-making and managerial action (Merchant \& Van der Stede, 2012; Otley, 1980), comprising elements such as performance feedback and reward structure (Bonner \& Sprinkle, 2002; Luckett \& Eggleton, 1991; Malmi \& Brown, 2008). In particular, we examine the effects of feedback frequency on intertemporal choices and the moderating role of reward timing.

Feedback has been recognized by the literature on work motivation as an important motivation tool that contributes to goal achievement and task performance (Latham, 2012). Feedback allows employees to compare their actual performance to pre-set goals, not only driving employees' behavior in a backward fashion by indicating when actions are needed to reduce deviations, but also driving employees' behavior in a feed-forward fashion by allowing them to learn better ways to perform their tasks (Pitkänen \& Lukka, 2011). As one of its dimensions, the frequency with which individuals receive feedback information is expected to affect individual behavior and task performance (Luckett $\&$ Eggleton, 1991). Feedback frequency has also been identified as a performance management practice organizations should revise in order to adapt to changes in the work environment (Ewenstein, Hancock, \& Komm, 2016). Thus, the importance of feedback frequency for organizations resides in its potential for leading to suboptimal decisions if feedback information is not provided at appropriate intervals (Latham, 2012). Prior research has dedicated a great deal of attention to the role of feedback frequency in individual decision making (e.g., Chhokar \& Wallin, 1984; Lam, DeRue, Karam, \& Hollenbeck, 2011; Lurie \& Swaminathan, 2009; Thornoch, 2016). 
As to the reward structure, prior literature on economics and psychology has recognized the motivational effects of providing monetary incentives to individuals (Latham, 2012; Prendergast, 1999). As one of the components of the reward structure, reward timing refers to the amount of time managers have to wait before receiving their rewards (Bonner \& Sprinkle, 2002). Individuals typically prefer to receive their rewards immediately due to delay discounting (Kirby \& Santiesteban, 2003) because waiting for a reward requires mental effort (Thaler, 1981). Thus, immediate rewards may have higher motivational effects than delayed rewards. For the purposes of this research, the importance of reward timing for organizations lies in its effects on risk-taking behavior, such as long-term decision making (Hartmann \& Slapničar, 2016; Prelec \& Loewenstein, 1991)

To examine the effects of feedback frequency on intertemporal choices and the moderating role of reward timing, we collect survey data from 78 middle-level managers working at a Brazilian company. The main contribution of this research to the management and accounting literature on intertemporal choices is twofold. First, little is known about the effect of feedback frequency on intertemporal choices. Bhojraj and Libby (2005) investigate the effect of disclosure frequency of mandatory external report on myopic behavior in the presence of capital market pressure and find that, in the presence of strong capital market pressure, managers behave more myopically when more frequent disclosure is provided. We then verify if the same pattern of results holds in a setting in which feedback is not mandatory, provided for internal purposes, and in which there is no capital market pressure. Second, previous literature investigating how feedback frequency affect individual decision making does not disentangle its effect on intertemporal choices from the effect of reward timing (Bellemare, Krause, Kröger, \& Zhang, 2005; Gneezy $\&$ Potters, 1997). We disentangle these two components and offer empirical evidence on the relation between feedback frequency and intertemporal choices and on the moderate role of reward timing in this relation.

The paper is structured as follows: in the next section, we review the relevant literature on intertemporal choices and develop our two hypotheses; we then describe our sample and data collection process, followed by the data analysis; finally, we discuss the main implications, limitations, and opportunities for future research.

\section{Literature Review and Hypotheses Development}

\section{I Intertemporal choices}

Intertemporal choices represent the trade-offs individuals make between benefits and costs occurring in the short- versus long-term (Frederick, Loewenstein, \& O’Donoghue, 2002). The practical importance of understanding these choices is its potential effects on organizations. Intertemporal choices causing short-term benefits may also result in long-term harm, such as when a decision maker opts for postponing an investment (e.g., purchase of a new equipment), even though this choice may compromise the organizational capacity of creating long-term value. A great debate exists over the harmful effects of shorttermism, that is, intertemporal choices in which organizations focus on short-term financial results at the expense of long-term value creation. The problem with organizational short-termism is that long-term oriented organizations are shown to perform better than those focusing on short-term results (Rajgopal, 2017).

When trying to understand the determinants of intertemporal choices, the literature in psychology has dedicated attention to the role of cognitive processes associated with incentive schemes (Berns, Laibson, \& Loewenstein, 2007; Soman, et al., 2005; Frederick et al., 2002). In turn, the business literature suggests three main determinants to explain intertemporal choices: organizational, individual, and economic (Laverty, 1996). Marginson and 
McAulay (2008) show that the understanding of managerial short-termism may consider not only economic dimensions, such as capital market pressure and performance management systems, but also individual (e.g., cognitive processes) and organizational dimensions.

The accounting literature has mostly focused on economic motives to explain intertemporal choices (Aguiar, 2011). In particular, the focus has been on identifying the best way to combine different performance measures in order to induce managers to balance their effort between the short- and long-term financial consequences of their actions (Abernethy et al., 2013; Aguiar et al., 2014; Banker \& Datar, 1989; Farrel et al., 2008; Feltham \& Xie, 1994; Pinheiro, Galdi, \& Oyadomari, 2012; Santos, 2015). The main expectation of this literature is that the use of financial performance measures (e.g., profit) leads managers to focus on short-term actions; while the inclusion of either non-financial or return measures induces them to better balance intertemporal choices (Abernethy et al., 2013).

In this paper, we examine the effects of two components of performance management systems, that is, feedback frequency and reward timing. These components entail economic, motivational and cognitive effects on individual behavior generally and on managerial intertemporal choices specifically. We extend prior literature in accounting by examining components of performance management systems that have not only economic effects, but also cognitive influences due to the way performance and rewarding information is framed.

\section{2 Feedback frequency and intertemporal choices}

Feedback affects motivation by providing individual performance information (Latham \& Locke, 1991; Locke, Shaw, Saari, \& Latham, 1981). Feedback information changes the individuals' beliefs that the minimal level of performance will be achieved and that the performance-contingent rewards will be received (Luckett \& Eggleton, 1991). Decision makers typically rely on performance feedback information when deciding to which problems they should drive their attention (Joseph, Klingebiel, \& Wilson, 2016). The accounting literature has acknowledged the role of feedback as a fundamental component of the performance management systems (e.g., Ferreira \& Otley, 2009; Malmi \& Brown, 2008). In particular, the provision of feedback is important because it allows decision makers to be aware of current results, which is a fundamental aspect for continually improving and succeeding in dynamic contexts (Luckett \& Eggleton, 1991).

While feedback may be comprised of different dimensions (Luckett \& Eggleton, 1991), we focus on the frequency with which feedback is provided. Prior research shows that more frequent feedback contributes to better performance because it allows decision makers to quickly react to environmental changes and envision the consequences of their actions (Lurie \& Swaminathan 2009). Similarly, the managerial cybernetic control concept suggests that the provision of timely performance information results in more sophisticated and useful information for addressing dynamic environments (Chenhall, 2003; Chenhall \& Morris, 1986).

However, this expectation has been challenged and empirical evidence demonstrates that more frequent feedback is not always better (Lam et al., 2011). For instance, Chhokar and Wallin (1984) show that weekly feedback does not result in better performance when compared to biweekly feedback. In another example, Lurie and Swaminathan (2009) indicate that more frequent feedback negatively affects performance in uncertain environments. Because higher feedback frequency leads individuals to focus on the most recent feedback and increases the cognitive demands on individuals to respond and process feedback information (Lam et al., 2011; Lurie \& Swaminatham, 2009), managers will have their ability to successfully exert self-control 
impaired. The reduced ability to exert self-control is expected to lead individuals to behave more impulsively (Ozdenoren, Salant, \& Silverman, 2012). As a consequence, managers will allocate more effort on short- than long-term tasks when they receive more frequent feedback information (e.g., Bhojraj \& Libby, 2005; Kraft, Vashishtha, \& Venkatachalam, 2018).

Nevertheless, less frequent feedback may not necessarily be the most appropriate solution in inducing managers to better balance their effort between tasks with different temporal effects on firm financial results. Less frequent feedback implies that too much information may be available at once to be processed by managers, resulting in information overload effects (Thornock, 2016). One of the potential effects of overload information is more cognitive effort in processing information (Payne, Bettman, \& Johnson, 1993) that may further lead individuals to spend more time in short-term tasks than long term tasks.

Prior research has then indicated that the relation between the amount of information processed and individual intertemporal choices may actually follow an inverted-U shape (Lam et al., 2011; Thornock, 2016), in which neither more nor less feedback frequency results in more balanced intertemporal choices. We then hypothesize that managers allocate more effort to longer-term tasks when they receive feedback frequency at intermediate levels, such as quarterly performance feedback, than either lower (e.g., up to a month) or higher (e.g., longer than quarterly) feedback frequencies. We do not anticipate any differences in the time managers allocate to longversus short-term tasks between up to a month feedback and longer than quarterly feedback. We formulate our first hypothesis as follows:

H1: Relative to short-term tasks, managers will allocate more time to longer-term tasks when they receive quarterly feedback than when they receive either up to a month feedback or longer than quarterly feedback.

\subsection{Feedback frequency, reward timing and intertemporal choices}

Feedback frequency and reward timing are two components of the performance management system and may operate as a package (Chenhall, 2003; Malmi \& Brown, 2008; Otley, 1980). We then examine if reward timing, that is, the amount of time managers have to wait before receiving their rewards, moderates the relationship between feedback frequency and intertemporal choices. Individuals typically prefer to receive their rewards immediately due to delay discounting (Kirby \& Santiesteban, 2003). Another reason individuals prefer immediate rewards is because waiting for a reward requires mental effort (Thaler, 1981).

We therefore expect that reward timing will moderate the relationship between feedback frequency and intertemporal choices as long as the effect of the two components of the performance measurement systems operate as a package, that is, their effects on individual behavior cannot only be considered in isolation. In particular, we hypothesize that the relationship between feedback frequency and more time allocated to long-term tasks relative to short-term tasks is more positive when managers receive their rewards with short-time delay, instead of long-time delay. We formulate our second hypothesis as follows:

H2: The relationship between feedback frequency and the time managers allocate to longer-term tasks is more positive when the reward timing is short versus long.

\section{Research Method}

\section{I Sample, data collection, and data analysis}

In order to test our hypotheses, we collect data through a survey with middle-level managers from a Brazilian organization in the iron and steel industry. We chose our company by convenience among those listed as the biggest and better companies in Brazil, in 2012. The company is 
part of a Brazilian conglomerate that is present in more than 20 countries and its main operations are in the zinc, nickel and aluminum markets. In 2016, the company's net revenues were US $\$ 1,844$ million and the capital expenditure was US $\$ 183$ million, which may be seen as an indicator of the importance that long-term investments have for the company. Relevant for the purpose of our research is the fact that the company does not have to disclose financial information, suggesting that this non-mandatory reporting setting may imply less external market pressures for attaining short-term profits.

We pre-tested our survey instrument with researchers who had prior experience in the development and application of questionnaires. The pre-test resulted in adjustments to content and presentation of the questionnaire, as well as allowed us to estimate the time required to complete the survey instrument. We sent an online survey in 2012 to 138 middle-level managers. We followed some procedures in order to increase the response rate. First, we contacted the Human Resources (HR) Department to ask for consent and for the list middle-level managers with their emails. Second, following the total design method, we sent multiple messages to our sample with two-weeks interval (Dillman, 2007). Third, after the first round of messages, we started a second round of messages sent to the remaining managers. In total, we received 78 useful questionnaires, which represents a response rate of 57 percent.

The respondents perform different functions within the organization, including sales, production, and administrative tasks. At the time of the data collection, they had worked for the company an average of 10.9 years and in their current function an average of 3.7 years. In addition, they expected to work for the company an average of 16 years more before retirement. The respondents received 60.6 percent of their reward in the form of a fixed salary, that is, not dependent on employee performance. Short-term incentives, including fixed salary, annual bonuses and profit sharing, represent 31.4 percent of their total compensation. Finally, 90.1 percent of the respondents are at most three levels distant from the chief executive officer.

To examine the effects of feedback frequency on intertemporal choices and the moderating role of reward timing, we use Multivariate Analysis of Covariance (MANCOVA). This statistical tool allows the simultaneous analysis of the two dimensions of the dependent variable (Hair, Anderson, Tatham, \& Black, 1998), as we will explain next. In addition, MANCOVA is a statistical tool that best fits the purpose and data of this research by allowing the examination of dependence relationships between two nonmetric independent variables and two dimensions of the metric dependent variable (Hair et al., 1998). Finally, MANCOVA allows for the inclusion of control variables as covariates in the analysis.

\subsection{Measurement instruments}

To measure intertemporal choices, we ask respondents to indicate the amount of time, in percentage form, they currently spend on tasks affecting the financial results (operational profit) of their unit and/or company within (i) one month or less, (ii) between one and three months, (iii) between three months and one year, (iv) between one and five years and (v) more than five years (Abernethy et al., 2013). Based on these categories, we form three groups representing relevant accounting periods: within the first quarterly reporting period (categories 1 and 2), within the annual reporting period (category 3 ), and beyond the annual reporting period (categories 4, 5, and 6). We label these groups short-, medium-, and long-term orientation, respectively. Next, we compute two log-ratios (Abernethy et al., 2013): $\log$ (long/short), to measure the time spent on long-term relative to short-term activities, and Log(medium/short), to measure the time spent on medium-term relative to short-term activities. We use these two logratios as the dependent variables in the statistical analysis. 
We measure feedback frequency by asking respondents to indicate the frequency with which they receive feedback information containing the most important measures for performance evaluation. Respondents should choose one of the following options: (i) daily, (ii) weekly, (iii) monthly, (iv) quarterly, (v) semiannually, and (vi) annually. We then create three groups: (i) up to a month (daily, weekly, and monthly), (ii) quarterly, and (iii) longer than quarterly (semiannual and annual). These three groups represent relevant feedback frequencies for disclosure purposes and for managerial performance evaluation (Bhojraj \& Libby, 2005; Frezatti, Aguiar, \& Guerreiro, 2007).

We develop a measure to capture reward timing by asking respondents to indicate how much time on average they typically wait to receive their pay for performance. Seven options are considered: (i) a few days, (ii) up to a week, (iii) up to a month, (iv) up to three months, (v) up to six months, (vi) up to a year, (vii) more than one year, and (viii) do not receive performance pay. No respondent has indicated the last category (viii), so we make no additional reference to this category in the results. We create two groups: (i) up to three months or short reward timing (a few days, up to a week, up to a month, and up to three months), and (ii) longer than three months or long reward timing (up to six months, up to a year, and more than one year). The use of three months as a cutoff point to separate short and long reward timing is due to the minimum interval of three months for Brazilian companies paying profit sharing to their employees. Profit sharing plans are prevalent in large Brazilian companies (Oliveira, 2014) and the employees of our company are entitled to receive part of their compensation in the form of an existing profit sharing plan.

We include two control variables in the analysis. The first one is the relative importance of traditional financial performance measures (Abernethy et al., 2013). We ask respondents to indicate the relative importance in percentage form that their superiors place on the following measures used for incentive purposes: (i) profit, (ii) return, (iii) cost, (iv) sales, (v) efficiency, (vi) quality, (vii) project, (viii) leadership, (ix) personal, and (x) others. We sum up the percentages indicated to the profit, cost and sales measures to compute our final measure capturing the relative importance of traditional financial measures.

The second control variable is decision strategy. Based on Payne et al. (1993), respondents should indicate the decision strategy that best describes their decision process in relation to the following six items on a five-point scale: (i) extent of compensatory trade-offs, (ii) amount of information ignored, (iii) use of selective information, (iv) focus on attributes versus alternatives of a decision, (v) evaluation formed, and (vi) focus on quantitative versus qualitative features. We sum up the rating attribute to the six items and create a variable capturing the respondent's decision strategy. The lower the rating, the closer the respondent's decision strategy is to a compensatory strategy, while the higher the rating, the closer is to a noncompensatory strategy. Our final variable is an indicator variable based on the median in which we code 1 for participants above the median, and 0 otherwise.

\section{Results}

Table 1 provides descriptive statistics for our independent variables. Up to a month is the predominant feedback frequency ( 47.4 percent), followed by longer than quarterly (38.5 percent), and quarterly (14.1 percent). As to reward timing, respondents receive 55.1 (44.9) percent of their rewards up to three months (longer than three months). Table 2 provides descriptive statistics for our intertemporal choice variable. The respondents allocate on average 51 (19) [30] percent of their effort on short- (medium-) [long-] term tasks. 
Table 1

Descriptive statistics_-Independent variables

\begin{tabular}{lcccccc}
\hline \multirow{2}{*}{$\begin{array}{l}\text { Feedback Frequency } \\
(\mathbf{n}=\mathbf{7 8})\end{array}$} & \multicolumn{2}{c}{ Percentages } & \multicolumn{2}{c}{ Percentages } \\
\cline { 2 - 3 } & Relative & Cumulated & & Relative & Cumulated \\
\hline Up to a month & 47.4 & 47.4 & Up to three months & 55.1 & 55.1 \\
Quarterly & 14.1 & 61.5 & Longer than three months & 44.9 & 100.0 \\
Longer than quarterly & 38.5 & 100.0 & Total & $\mathbf{1 0 0 . 0}$ & $\mathbf{1 0 0 . 0}$ \\
\hline Total & $\mathbf{1 0 0 . 0}$ & & &
\end{tabular}

Table 2

\section{Descriptive statistics-Dependent variables}

\begin{tabular}{lcccc}
\hline Intertemporal Choices $(\mathbf{n}=\mathbf{7 8})$ & Average Frequency & Standard Deviation & Minimum & Maximum \\
\hline Time spent on short-term tasks & 0.51 & 0.30 & 0.02 & 0.97 \\
Time spent on medium-term tasks & 0.19 & 0.14 & 0.02 & 0.50 \\
Time spent on long-term tasks & 0.30 & 0.28 & 0.02 & 0.97 \\
\hline
\end{tabular}

Table 3 shows the correlation matrix with our main variables. As expected, a significant correlation exists between the two dimensions of the dependent variable. Supporting prior studies (Abernethy et al. 2013), the relative importance of financial performance measures is negatively and significantly associated with the two dimensions of intertemporal choices. The relationship between reward timing and the weight placed on financial measures is also negative and marginally significant, suggesting that when employees receive their rewards with a longer delay, their performance is less based on financial dimensions.

Table 3

\section{Correlations (Pearson)}

\begin{tabular}{|c|c|c|c|c|c|}
\hline Variables $(\mathrm{n}=78)$ & $\begin{array}{c}\text { Long intertemporal } \\
\text { choice }\end{array}$ & $\begin{array}{l}\text { Feedback } \\
\text { frequency }\end{array}$ & $\begin{array}{c}\text { Reward } \\
\text { timing }\end{array}$ & $\begin{array}{l}\text { Financial } \\
\text { measures }\end{array}$ & $\begin{array}{r}\text { Decision } \\
\text { strategy }\end{array}$ \\
\hline Medium intertemporal choice & $\begin{array}{r}0.743^{* * *} \\
(0.000) \\
\end{array}$ & $\begin{array}{c}0.031 \\
(0.789) \\
\end{array}$ & $\begin{array}{l}-0.152 \\
(0.184)\end{array}$ & $\begin{array}{c}-0.256^{* *} \\
(0.023) \\
\end{array}$ & $\begin{array}{l}-0.990 \\
(0.388)\end{array}$ \\
\hline Long intertemporal choice & - & $\begin{array}{c}0.054 \\
(0.641) \\
\end{array}$ & $\begin{array}{l}-0.092 \\
(0.423) \\
\end{array}$ & $\begin{array}{c}-0.235^{* *} \\
(0.038)\end{array}$ & $\begin{array}{l}-0.144 \\
(0.210) \\
\end{array}$ \\
\hline Feedback frequency & - & - & $\begin{array}{l}-0.136 \\
(0.236) \\
\end{array}$ & $\begin{array}{l}-0.119 \\
(0.301) \\
\end{array}$ & $\begin{array}{c}0.024 \\
(0.835) \\
\end{array}$ \\
\hline Reward timing & - & - & - & $\begin{array}{l}-0.219^{*} \\
(0.054)\end{array}$ & $\begin{array}{l}-0.067 \\
(0.559)\end{array}$ \\
\hline Financial measures & - & - & - & - & $\begin{array}{c}0.041 \\
(0.718)\end{array}$ \\
\hline
\end{tabular}

Note. Medium intertemporal choice captures the time spent on medium-term tasks in relation to short-term tasks; Long intertemporal choice captures the time spent on long-term tasks in relation to short-term tasks; Feedback frequency includes three groups_-short (up to a month), medium (quarterly), and long (longer than quarterly); Reward timing includes two groups — short (delay of up to three months) and long (delay of longer than three months); Decision strategy is an indicator variable coded 1 if the respondent uses non-compensatory decision strategies, 0 otherwise.

*, ** Correlation is significant at the 0.10 and 0.05 levels, respectively (two-tailed tests). 


\section{I The role of feedback frequency}

We use MANCOVA to test our hypotheses, with time spent on medium-term tasks in relation to short-term tasks and time spent on long-term tasks in relation to short-term tasks as the two dimensions of our dependent variables and feedback frequency and reward timing as the independent variables. We use one-tailed $p$-values for directional predictions and two-tailed $p$-values for all other tests.
Our first hypothesis predicts that, relative to the time allocated to short-term tasks, the time allocated to either medium- or long-term tasks is higher when managers receive quarterly feedback frequency than in the other two feedback frequencies - that is, up to a month and longer than quarterly. Table 4 shows that the main effect of feedback frequency is significant $(\mathrm{F}=1.92$, $p=0.06$, Wilks' lambda, one-tailed).

Table 4

\section{Multivariate analysis}

\begin{tabular}{|c|c|c|c|c|c|c|}
\hline Effect & Tests & Value & df-between groups & df-within groups & $\mathbf{F}$ & $p$-value \\
\hline \multirow{4}{*}{ Model } & W & 0.50 & 42 & 110 & 1.08 & 0.37 \\
\hline & $\mathrm{P}$ & 0.57 & 42 & 112 & 1.08 & 0.36 \\
\hline & $\mathrm{L}$ & 0.83 & 42 & 108 & 1.07 & 0.38 \\
\hline & $\mathrm{R}$ & 0.53 & 21 & 56 & 1.44 & 0.14 \\
\hline \multirow{4}{*}{ Feedback frequency } & W & 0.87 & 4 & 110 & 1.92 & $0.06^{*}$ \\
\hline & $\mathrm{P}$ & 0.13 & 4 & 112 & 1.89 & $0.06^{*}$ \\
\hline & $\mathrm{L}$ & 0.14 & 4 & 108 & 1.94 & $0.05^{*}$ \\
\hline & $\mathrm{R}$ & 0.14 & 2 & 56 & 3.90 & $0.01^{* * *}$ \\
\hline \multirow{4}{*}{ Reward timing } & W & 0.94 & 2 & 55 & 1.88 & 0.16 \\
\hline & $\mathrm{P}$ & 0.06 & 2 & 55 & 1.88 & 0.16 \\
\hline & $\mathrm{L}$ & 0.07 & 2 & 55 & 1.88 & 0.16 \\
\hline & $\mathrm{R}$ & 0.07 & 2 & 55 & 1.88 & 0.16 \\
\hline \multirow{4}{*}{ Feedback frequency ${ }^{*}$ Reward timing } & W & 0.85 & 4 & 110 & 2.24 & $0.07^{*}$ \\
\hline & $\mathrm{P}$ & 0.15 & 4 & 112 & 2.24 & $0.07^{*}$ \\
\hline & $\mathrm{L}$ & 0.17 & 4 & 108 & 2.25 & $0.07^{*}$ \\
\hline & $\mathrm{R}$ & 0.14 & 2 & 56 & 3.99 & $0.02^{* *}$ \\
\hline \multirow{4}{*}{ Financial measures } & W & 0.61 & 30 & 110 & 1.01 & 0.46 \\
\hline & $\mathrm{P}$ & 0.43 & 30 & 112 & 1.03 & 0.44 \\
\hline & $\mathrm{L}$ & 0.55 & 30 & 108 & 1.00 & 0.48 \\
\hline & $\mathrm{R}$ & 0.32 & 15 & 56 & 1.20 & 0.30 \\
\hline \multirow{4}{*}{ Decision strategy } & W & 0.96 & 2 & 55 & 1.19 & 0.31 \\
\hline & $\mathrm{P}$ & 0.04 & 2 & 55 & 1.19 & 0.31 \\
\hline & $\mathrm{L}$ & 0.04 & 2 & 55 & 1.19 & 0.31 \\
\hline & $\mathrm{R}$ & 0.04 & 2 & 55 & 1.19 & 0.31 \\
\hline
\end{tabular}

Note. Main variables are defined as in Table 3.

*, **, *** Effects are significant at the 0.10, 0.05 and 0.01 levels. W-Wilks' lambda; L-Lawley-Hotelling trace; P-Pillai's trace; R-Roy's largest root. Bolded values are hypothesized directional relationships and, thus, one-tailed p-values.

Figure 1 plots the patterns of the means of medium intertemporal choices as well as long intertemporal choices. Table 5 indicates the results of paired t-tests. Results show that the mean of medium intertemporal choices is significantly higher when the feedback frequency is quarterly $(-0.23)$ than when it is up to a month $(-0.53)$ $(\mathrm{t}-1.34$; one-tailed; $p=0.10)$. However, the mean of medium intertemporal choices does not differ across quarterly and longer than quarterly $(-0.49)$ feedback frequencies ( $\mathrm{t}$ 1.02; one-tailed; $p=$ 0.16). Finally, the mean of medium intertemporal choices does not differ across up to a month and longer than quarterly feedback frequency $(\mathrm{t}-0.21$; two-tailed; $p=0.83$ ). 


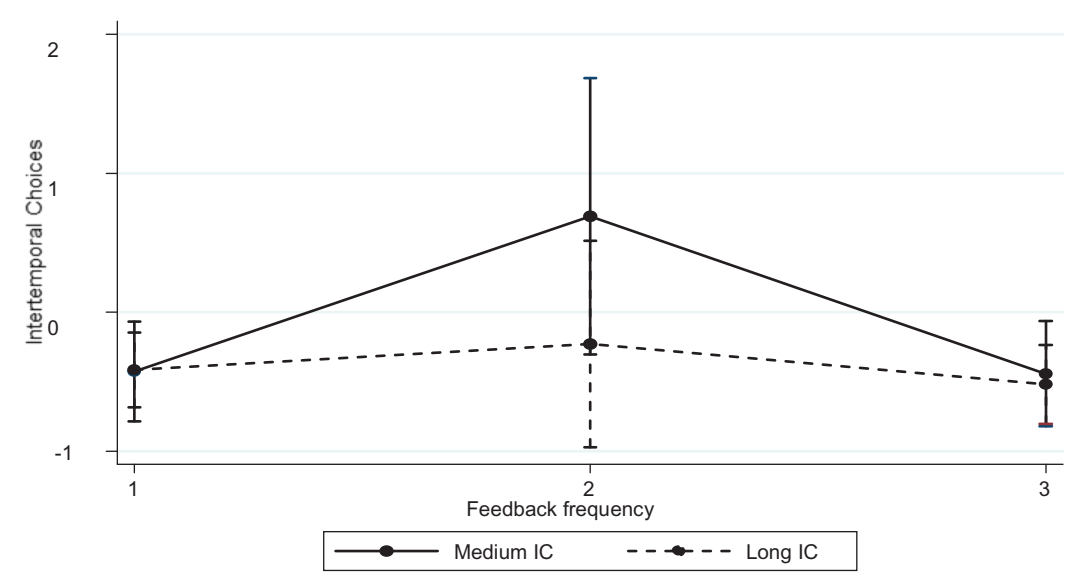

Figure 1. Mean intertemporal choices by feedback frequency

Table 5

Paired t-tests - main effect of feedback frequency

\begin{tabular}{|c|c|c|c|c|c|c|c|c|c|}
\hline \multirow{2}{*}{ Feedback frequency } & \multirow{2}{*}{$\mathbf{N}$} & \multicolumn{4}{|c|}{ Medium intertemporal choices } & \multicolumn{4}{|c|}{ Long intertemporal choices } \\
\hline & & Mean & Std. Dev. & $\mathbf{t}$ & $p$-value & Mean & Std. Dev. & $\mathbf{t}$ & $p$-value \\
\hline Up to a month $\mathrm{x}$ & 37 & -0.53 & 0.59 & \multirow{2}{*}{-1.34} & \multirow{2}{*}{$0.10^{*}$} & -0.54 & 0.88 & \multirow{2}{*}{-1.87} & \multirow{2}{*}{$0.04^{* *}$} \\
\hline Quarterly & 11 & -0.23 & 0.67 & & & 0.18 & 1.19 & & \\
\hline Quarterly x & 11 & -0.23 & 0.67 & \multirow{2}{*}{1.02} & \multirow{2}{*}{0.16} & 0.18 & 1.19 & \multirow{2}{*}{1.54} & \multirow{2}{*}{$0.07^{*}$} \\
\hline Longer than quarterly & 30 & -0.49 & 0.86 & & & -0.44 & 1.04 & & \\
\hline Up to a month $\mathrm{x}$ & 37 & -0.53 & 0.59 & \multirow{2}{*}{-0.21} & \multirow{2}{*}{0.83} & -0.54 & 0.88 & \multirow{2}{*}{-0.40} & \multirow{2}{*}{0.69} \\
\hline Longer than quarterly & 30 & -0.49 & 0.86 & & & -0.44 & 1.04 & & \\
\hline
\end{tabular}

Note. *, ** Effects are significant at the 0.10 and 0.05 levels. Bolded values are hypothesized directional relationships and, thus, one-tailed p-values.

Results also show that the mean of long intertemporal choices are significantly higher when the feedback frequency is quarterly $(0.18)$ than when it is either up to a month $(-0.54)$ ( $\mathrm{t}-1.87$; one-tailed; $p=0.04$ ) or longer than quarterly (-0.44) (t 1.54; one-tailed; $p=0.07$ ). Finally, the mean of long intertemporal choices does not differ across up to a month and longer than quarterly feedback frequency $(\mathrm{t}-0.40$; twotailed; $p=0.69)$. Overall, our results support prior studies (e.g., Lam et al., 2011; Thornock, 2016) and our expectations that managerial intertemporal choices are longer-term oriented when respondents receive quarterly versus up to a month feedback for both dimensions of intertemporal choices. Further, consistent with prior studies (e.g., Lam et al., 2011; Thornock, 2016), our results support the expectation that managerial intertemporal choices are longer-term oriented when our respondents receive quarterly versus longer than quarterly feedback for longterm tasks relative to short-term tasks, while we fail to find significant differences across these two feedback frequencies for medium-term tasks relative to short-term tasks. Finally, managerial intertemporal choices do not differ across up to a month and longer than quarterly feedback frequencies for both dimensions of intertemporal choices.

As to the control variables, Table 4 indicates that neither the relative importance of traditional financial performance measures nor the decision strategy significantly affects intertemporal decision making. The non-significant effect of traditional financial performance measures is surprising as most of the prior research in accounting indicates 
that a higher weight placed on these measures results in shorter-term decision making (e.g., Abernethy et al., 2013; Aguiar et al., 2014). In turn, the non-significant effect of decision strategy is not consistent with the expectation that the use of compensatory strategies consume more cognitive resources, which is expected to lead to a focus on short-term results (Loewenstein \& O’Donoghue, 2005; Payne et al., 1993).

\subsection{The moderating role of rewarding time}

Our second hypothesis predicts that the relationship between feedback frequency and the time managers allocate to longer-term tasks is more positive when the reward timing is short versus long. Consistent with the expectation that the components of the performance management system may operate as a package (e.g., Chenhall, 2003; Malmi \& Brown, 2008; Otley, 1980), Table 4 confirms a significant interaction between feedback frequency and reward timing ( $\mathrm{F}=2.24, p=0.07$, Wilks' lambda, two-tailed). To better understand the pattern of interaction, Figure 2 plots the means of (medium and long) intertemporal choices and Table 6 presents the results of paired t-tests for the three frequencies of feedback.

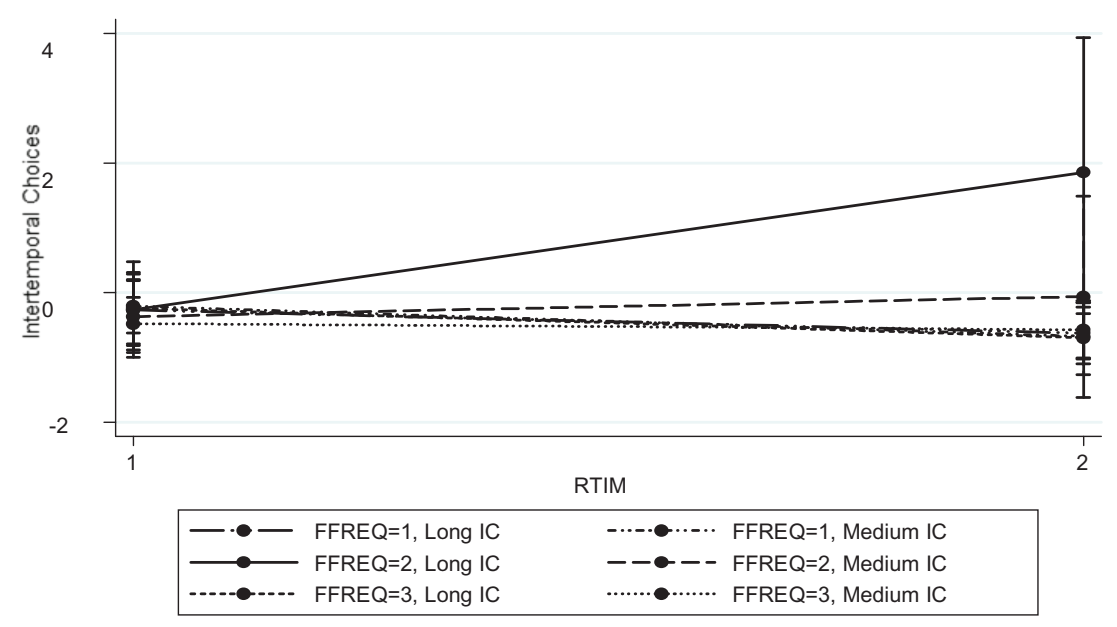

Figure 2. Mean intertemporal choices by feedback frequency and reward timing

Table 6

\section{Paired t-tests - interactive effect}

\begin{tabular}{|c|c|c|c|c|c|c|c|c|c|}
\hline \multirow{2}{*}{$\begin{array}{l}\text { Reward timing } x \\
\text { up to a month feedback }\end{array}$} & \multirow{2}{*}{$\mathbf{N}$} & \multicolumn{4}{|c|}{ Medium intertemporal choices } & \multicolumn{4}{|c|}{ Long intertemporal choices } \\
\hline & & Mean & Std. Dev. & $\mathbf{t}$ & $p$-value & Mean & Std. Dev. & t & $p$-value \\
\hline Short reward timing $\mathrm{x}$ & 16 & -0.39 & 0.50 & \multirow{2}{*}{1.30} & \multirow{2}{*}{$0.10^{*}$} & -0.54 & 0.91 & \multirow{2}{*}{0.02} & \multirow{2}{*}{0.49} \\
\hline Long reward timing & 21 & -0.63 & 0.65 & & & -0.54 & 0.88 & & \\
\hline \multirow{2}{*}{$\begin{array}{l}\text { Reward timing } \mathrm{x} \\
\text { quarterly feedback }\end{array}$} & & \multicolumn{4}{|c|}{ Medium intertemporal choices } & \multicolumn{4}{|c|}{ Long intertemporal choices } \\
\hline & $\mathrm{N}$ & Mean & Std. Dev. & $\mathrm{t}$ & $p$-value & Mean & Std. Dev. & $\mathrm{t}$ & $p$-value \\
\hline Short reward timing $\mathrm{x}$ & 10 & -0.25 & 0.70 & & & 0.03 & 1.13 & & \\
\hline Long reward timing & 1 & 1.76 & - & - & - & 1.76 & - & - & - \\
\hline \multirow{2}{*}{$\begin{array}{l}\text { Reward timing x longer } \\
\text { than quarterly feedback }\end{array}$} & & \multicolumn{4}{|c|}{ Medium intertemporal choices } & \multicolumn{4}{|c|}{ Long intertemporal choices } \\
\hline & $\mathrm{N}$ & Mean & Std. Dev. & $\mathrm{t}$ & $p$-value & Mean & Std. Dev. & $\mathrm{t}$ & $p$-value \\
\hline Up to a month $\mathrm{x}$ & 17 & -0.43 & 0.86 & & & -0.31 & 1.08 & & \\
\hline Quarterly & 13 & -0.56 & 0.88 & 0.41 & 0.34 & -0.61 & 1.00 & $0 . / 8$ & 0.22 \\
\hline
\end{tabular}

Note. ${ }^{*}$ Effects are significant at the 0.10 level. Bolded values are hypothesized directional relationships and, thus, one-tailed p-values. 
For up to a month feedback, results show that the medium intertemporal choices are significantly higher when the reward timing is short (-0.39) than when it is long (-0.63) (t 1.30; one-tailed; $p=0.10$ ). However, the mean of long intertemporal choices does not differ across short $(-0.54)$ and long (-0.54) reward timing (t 0.02; one-tailed; $p=0.49)$. For quarterly frequency, we could not run paired t-tests due to the reduced number of observations for long reward timing, while the mean of both medium and long intertemporal choices does not differ across shortand long-reward timing when the frequency of feedback is longer than quarterly. Therefore, in our sample, the moderate role of reward timing on the relationship between feedback frequency and intertemporal choices is mainly explained by short reward timing relative to long reward timing resulting in more time allocated to mediumversus short-term tasks when managers receive up to a month feedback. Finally, untabulated results confirm that our two control variables are not significant.

\section{Conclusion}

We examine in this paper the role of two components of the performance management systems in explaining how middle-level managers of a single company allocate time and effort among tasks with different temporal effects on financial results. These two components of the performance management systems are comprised not only of economic features, but also behavioral and cognitive aspects. While prior research on feedback frequency suggests that more frequent feedback may have positive effects on performance (see e.g. Lurie \& Swaminathan, 2009), our results indicate that this improvement in performance is due to an excessive focus on short-term tasks at the expense of the longer-term consequences of managerial actions. This result is consistent with prior studies indicating that more frequent feedback leads to managerial myopic behavior (Bhojraj \& Libby, 2005). More importantly, we show that managers allocate more time to longer- term tasks when they receive quarterly feedback as opposed to either up to a month or longer than quarterly feedback. This result is consistent with prior results and our first hypothesis suggesting an inverted-U relationship between feedback frequency and performance (e.g., Lam et al., 2011; Thornock, 2016).

Supporting prior accounting literature (e.g., Chenhall, 2003; Malmi \& Brown, 2008; Otley, 1980), our results also suggest that feedback frequency and reward timing operate as a package as long as reward timing moderates the relationship between feedback frequency and intertemporal choices. Prior studies on intertemporal choices point out that individuals have a preference for immediate rather than delayed rewards due to delay discounting and cognitive effort (Kirby $\&$ Santiesteban, 2003; Thaler, 1981). Consistent with our second hypothesis, we show that short reward timing increases the effort managers allocate to medium- versus short-term tasks when managers receive up to a month feedback.

Our results contribute to the accounting literature focused on understanding the effects of feedback frequency on intertemporal choices (e.g., Bhojraj \& Libby, 2005; Kraft et al., 2018). In particular, in a setting in which reporting is not mandatory, we provide support to the expectation that neither higher nor lower feedback frequencies are necessarily better when managers are making intertemporal choices. This result is consistent with psychological literature indicating that either higher or lower levels of information processing may harm task performance, suggesting that feedback frequency shows an inverted-U relationship with task performance (Lam et al., 2011). This result is also consistent with prior research in accounting indicating that the timing of performance feedback exhibits an inverted-U relationship with future individual performance (Thornock, 2016). We add to this literature by showing that not only the timing of performance feedback, but also the frequency with which performance feedback is provided, show an inverted-U relationship with managerial intertemporal choices. 
Our results also contribute to the accounting literature that emphasizes the importance of taking into consideration the links between the components of the performance management system (Chenhall, 2003; Fisher, 1998; Malmi \& Brown, 2008). Our results are particularly important given the fact that prior empirical evidence has not offered strong support to the expectation of a joint effect of feedback and other components of the performance management system on individual performance (Bonner \& Sprinkle, 2002; Lourenço, 2016). In particular, we show that reward timing moderates the relationship between feedback frequency and managerial intertemporal choices mainly by a short-reward timing increasing the time allocated to medium-term tasks relative to short-term tasks when managers receive up to a month feedback. We then support the expectation that these two components of the performance management system operate as a package.

Our results have limitations that also represent avenues for future research. First, we examine a single company whose strategic objective may play a role in the way middle-level managers make intertemporal choices. While this feature of our research setting may reduce the variability of our results, we collect data from managers working at different hierarchical levels and in different functions and find that their intertemporal choices vary with changes in the levels of the two components of the performance management system. Future research could examine if feedback frequency and reward timing also affect managerial intertemporal choices across a wide range of organizations and industries.

Second, future research could take into consideration a larger number of components of the performance management system to investigate if the relation of a particular component with individual decision making and performance depends on the levels of the other components. In this research, we consider two components - that is, feedback frequency and reward timing - and control for the weight placed on financial performance measures. It is possible that the relationship between feedback frequency and intertemporal choices depends not only on the reward timing, but also on the reward timing and the weight placed on different performance measures. Future research could examine this possibility by collecting a large number of observations that allow testing threeway interactions.

Third, future research could use more objective measures rather than self-report measures to capture our main variables. For instance, future research could use archival data on the actual feedback frequency and reward timing an organization uses for evaluation and rewarding purposes, as well as actual information indicating how managers allocate financial resources among different projects. Fourth, because we collect data of 78 middle-level managers of a single company, future research could consider a larger sample, including different hierarchical levels to increase the generalizability of the results.

Finally, our single-entity survey focused on employees' intertemporal choices. However, it is possible that how employees allocate their time and effort to short- versus long-term tasks may depend on the dynamics of superior-subordinate interactions, such as how superiors' personality traits affect the way they provide feedback to their subordinates and further affect the way subordinates make intertemporal choices.

\section{References}

Abernethy, M. A., Bouwens, J., \& Lent, L. van (2013). The role of performance measures in the intertemporal choices of business unit managers. Contemporary Accounting Research, 30(3), 925961.

Agrawal, A., Dinneen, B., \& Seth, I. (2016). Survey: Are today's CFOs ready for tomorrow's demands on finance?. McKinsey \& Company. Retrieved from http://www.mckinsey.com/ business-functions/strategy-and-corporatefinance/our-insights/are-todays-cfos-ready-fortomorrows-demands-on-finance 
Aguiar, A. B. (2011). Consistency in empirical accounting studies on managerial time orientation: A bibliographical analysis. BASE-Revista de Administração e Contabilidade da Unisinos, 8(4), 373-385.

Aguiar, A. B., Pinheiro, P. N., \& Oyadomari, J. C. T. (2014). How do different performance measures affect managerial time orientation? Empirical evidence from sales managers in the oil and gas industry. Advances in Accounting, incorporating Advances in International Accounting, 30(1), 143-153.

Banker, R. D., \& Datar, S. M. (1989). Sensitivity, precision, and linear aggregation of signals for performance evaluation. Journal of Accounting Research, 27(1), 21-39.

Bellemare, C., Krause, M., Kröger, S., \& Zhang, C. (2005). Myopic loss aversion? Information feedback versus investment flexibility. Economic Letters, 87(3), 319-324.

Berns, G. S., Laibson, D., \& Loewenstein, G. (2007). Intertemporal choice: Toward an integrative framework. Trends in Cognitive Sciences, 11(11), 482-488.

Bhojraj, S., \& Libby, R. (2005). Capital market pressure, disclosure frequency-induced earnings/ cash flow conflict, and managerial myopia. The Accounting Review, 80(1), 1-20.

Bonner, S. E., \& Sprinkle, G. B. (2002). The effects of monetary incentives on effort and task performance: Theories, evidence, and a framework for research. Accounting, Organizations and Society, 27(4-5), 303-345.

Chenhall, R. H. (2003). Management control systems design within its organizational context: Findings from contingency-based research and directions for the future. Accounting, Organizations and Society, 28(2-3), 127-168.

Chenhall, R. H., \& Morris, D. (1986). The impact of structure, environment, and interdependence on the perceived usefulness of management accounting systems. The Accounting Review, 61(1), 16-35.

Chhokar, J. S., \& Wallin, J. A. (1984). A field study of the effect of feedback frequency on performance. Journal of Applied Psychology, 69(3), 524-530.

Dillman, D. A. (2007). Mail and Internet Surveys. New York: John Wiley Professional.

Ewenstein, B., Hancock, B., \& Komm, A. (2016). Ahead of the curve: The future of performance management. McKinsey \& Company. Retrieved from https://www.mckinsey.com/ business-functions/organization/our-insights/ ahead-of-the-curve-the-future-of-performancemanagement

Farrel, A. M., Kadous, K., \& Towry, K. L. (2008). Contracting on contemporaneous versus forwardlooking measures: An experimental investigation. Contemporary Accounting Research, 25(3), 773802.

Feltham, G. A., \& Xie, J. (1994). Performance measure congruity and diversity in multi-task principal/agent relations. The Accounting Review, 69(3), 429-453.

Ferreira, A., \& Otley, D. (2009). The design and use of performance management systems: An extended framework for analysis. Management Accounting Research, 20(4), 263-282.

Fisher, J. G. (1998). Contingency theory, management control systems and firm outcomes: Past results and future directions. Behavioral Research in Accounting, 10, 47.

Frederick, S., Loewenstein, G., \& O'Donoghue, T. (2002). Time discounting and time preference: A critical review. Journal of Economic Literature, 40(2), 351-401.

Frezatti, F., de Aguiar, A. B., \& Guerreiro, R. (2007). Diferenciaçóes entre a contabilidade 
financeira e a contabilidade gerencial: Uma pesquisa empírica a partir de pesquisadores de vários países. Revista de Contabilidade e Finanças, 18(44), 9-22.

Gneezy, U., \& Potters, J. (1997). An experiment on risk taking and evaluation periods. The Quarterly Journal of Economics, 112(2), 631-645.

Hair, J. F., Jr., Anderson, R. E., Tatham, R. L., \& Black, W. C. (1998). Multivariate data analysis (5th ed). New Jersey: Prentice Hall.

Hartmann, F. G. H., \& Slapniĉar, S. (2016). Bonus scheme design and risk taking: Experimental evidence on the effect of deferred bonuses. The Journal of Management and Governance, 19(4), 875-896. Retrieved from https://repub.eur.nl/ pub/76667

Joseph, J., Klingebiel, R., \& Wilson, A. J. (2016). Organizational structure and performance feedback: Centralization, aspirations, and termination decisions. Organization Science, 27(5), 1065-1083.

Kraft, A. G., Vashishtha, R., \& Venkatachalam, M. (2018). Frequent financial reporting and managerial myopia. The Accounting Review, 93(2), 249-275.

Kirby, K. N., \& Santiesteban, M. (2003). Concave utility, transaction costs, and risk in measuring discounting of delayed rewards. Journal of Experimental Psychology: Learning, Memory, and Cognition, 29(1), 66-79.

Lam, C. F., DeRue, D. S., Karam, E. P., \& Hollenbeck, J. R. (2011). The impact of feedback frequency on learning and task performance: Challenging the "more is better" assumption. Organizational Behavior and Human Decision Processes, 116(2), 217-228.

Latham, G. P. (2012). Work motivation: History, theory, research, and practice (2nd ed.). Los Angeles: Sage.
Latham, G. P., \& Locke, E. A. (1991). Selfregulation through goal setting. Organizational behavior and human decision processes, 50(2), 212-247.

Laverty, K. J. (1996). Economic "short-termism": The debate, the unresolved issues, and the implications for management practice and research. Academy of Management Review, 21(3), 825-860.

Locke, E. A., Shaw, K. N., Saari, L. M., \& Latham, G. P. (1981). Goal setting and task performance: 1969-1980. Psychological bulletin, 90(1), 125-152.

Loewenstein, G., \& O’Donoghue, T. (2005). Animal spirits: Affective and deliberative processes in economic behavior (Working Paper No. 539843). Retrieved from Social Science Research Network - SSRN http://dx.doi.org/10.2139/ssrn.539843

Lourenço, S. M. (2016). Monetary incentives, feedback, and recognition: Complements or substitutes? Evidence from a field experiment in a retail services company. The Accounting Review, 91(1), 279-297.

Luckett, P. F., \& Eggleton, I. R. C. (1991). Feedback and management accounting: A review of research into behavioral consequences. Accounting, Organizations and Society, 16(4), 371-394.

Lurie, N. H., \& Swaminathan, J. M. (2009). Is timely information always better? The effect of feedback frequency on decision making. Organizational Behavior and Human Decision Processes, 108(2), 315-329.

Malmi, T., \& Brown, D. A. (2008). Management control systems as a package: Opportunities, challenges and research directions. Management Accounting Research, 19(4), 287-300.

Marginson, D., \& McAulay, L. (2008). Exploring the debate on short-termism: A theoretical and 
empirical analysis. Strategic Management Journal, 29(3), 273-292.

Matta, E., \& Beamish, P. W. (2008). The accentuated CEO career horizon problem: Evidence from international acquisitions. Strategic Management Journal, 29(7), 683-700.

Merchant, K. A., \& Van der Stede, W. A. (2012). Management control systems performance measurement, evaluation and incentives (3rd ed.). New York: Financial Times/Prentice Hall.

Oliveira, A. C. (2014, janeiro, 23). Benefício mais desejado é participação nos lucros. Você $S / A$. Retrieved from https://exame.abril.com.br/ carreira/para-todos-os-bolsos/

Otley, D. T. (1980). The contingency theory of management accounting: Achievement and prognosis. Accounting, Organizations and Society, 5(4), 413-428.

Ozdenoren, E., Salant, S. W., \& Silverman, D. (2012). Willpower and the optimal control of visceral urges. Journal of the European Economic Association, 10(2), 342-368.

Payne, J. W., Bettman, J. R., \& Johnson, E. J. (1993). The adaptive decision maker. Cambridge: Cambridge University Press.

Pinheiro, P. N., Galdi, F. C., \& Oyadomari, J. C. T. (2012). Effects of EVA ${ }^{\oplus}$ based management on intertemporal decisions: A study with sales managers. Revista de Administração, 47(2), 231248.

Pitkänen, H., \& Lukka, K. (2011). Three dimensions of formal and informal feedback in management accounting. Management Accounting Research, 22(2), 125-137.
Prelec, D., \& Loewenstein, G. (1991). Decision making over time and under uncertainty: A common approach. Management Science, 37(7), 770-786.

Prendergast, C. (1999). The provision of incentives in firms. Journal of economic literature, 37(1), 7-63.

Rajgopal, S. (2017). We can't study short-termism without the right metrics. Harvard Business Review. Retrieved from https://hbr.org/2017/04/ we-cant-study-short-termism-without-the-rightmetrics

Santos, L. P. G. (2015). Comparando o uso de mensuração forward-looking e contemporânea de desempenho na formulação de contratos de incentivo quando existe o problema do horizonte: Uma análise experimental. Revista Contabilidade \& Finanças, 26(68), 195-207.

Soman, D., Ainslie, G., Frederick, S., Li, X., Lynch, J., Moreau, P., Mitchell, A., ... Zauberman, G. (2005). The psychology of intertemporal discounting: Why are distant events valued differently from proximal ones?. Marketing Letters, 16(3-4), 347-360.

Souder, D., \& Shaver, J. M. (2010). Constraints and incentives for making long horizon corporate investments. Strategic Management Journal, 31(12), 1316-1336.

Thaler, R. (1981). Some empirical evidence on dynamic inconsistency. Economics Letters, 8(3), 201-207.

Thornock, T. A. (2016). How the timing of performance feedback impacts individual performance. Accounting, Organizations and Society, 55, 1-11. 


\section{Supporting Agencies:}

São Paulo Research Foundation (FAPESP)

\section{About the Authors:}

1. Andson Braga de Aguiar, Post Doctor, University of Waterloo, School of Accounting and Finance. Ontario, Canadá. E-mail:abraga@usp.br

ORCIID

(iD 0000-0003-4034-4134

2. José Carlos Tiomatsu Oyadomari, PhD, University of Sao Paulo, School of Economics, Business Administration, and Accountancy. São Paulo, Brazil. E-mail:oyadomari@mackenzie.br

ORCIID

(iD0000-0003-3059-3102

3. Cláudio Soerger Zaro, PhD, University of Sao Paulo, School of Economics, Business Administration, and Accountancy. São Paulo, Brazil. E-mail: claudiosz@uems.br

ORCIID

(D)0000-0002-7069-4410

\section{Preliminary Publications:}

- Short term versus long term: the role of evaluation period and reward timing. Aguiar, A. B., Oyadomari, J. C. T., Zaro, C. S. Conference on Performance Measurement and Management Control, Nice-France, 2015

- Short term versus long term: the role of evaluation period and reward timing. Aguiar, A. B., Oyadomari, J. C. T., Zaro, C. S. American Accounting Association Annual Meeting, Chicago-USA, 2015

\section{Derived from the following thesis:}

- Curto Prazo Versus Longo Prazo: O Papel de Esquemas de Incentivo e Estratégias de Decisão. Aguiar, A. B. University of Sao Paulo, School of Economics, Business Administration, and Accounting, 2015.

\section{Contribution of each author}

\begin{tabular}{|c|c|c|c|}
\hline Contribution & $\begin{array}{c}\text { Andson Braga } \\
\text { de Aguiar }\end{array}$ & $\begin{array}{l}\text { José Carlos Tiomatsu } \\
\text { Oyadomari }\end{array}$ & $\begin{array}{l}\text { Cláudio Soerger } \\
\text { Zaro } \\
\end{array}$ \\
\hline 1. Definition of research problem & $\sqrt{ }$ & & \\
\hline $\begin{array}{l}\text { 2. Development of hypotheses or research questions (empirical } \\
\text { studies) }\end{array}$ & $\sqrt{ }$ & $\sqrt{ }$ & \\
\hline 3. Development of theoretical propositions ( theoretical Work ) & $\sqrt{ }$ & $\sqrt{ }$ & \\
\hline 4. Theoretical foundation/ Literature review & $\sqrt{ }$ & $\sqrt{ }$ & $\sqrt{ }$ \\
\hline 5. Definition of methodological procedures & $\sqrt{ }$ & $\sqrt{ }$ & $\sqrt{ }$ \\
\hline 6. Data collection & $\sqrt{ }$ & & $\sqrt{ }$ \\
\hline 7. Statistical analysis & $\sqrt{ }$ & & $\sqrt{ }$ \\
\hline 8. Analysis and interpretation of data & $\sqrt{ }$ & $\sqrt{ }$ & $\sqrt{ }$ \\
\hline 9. Critical revision of the manuscript & $\sqrt{ }$ & $\sqrt{ }$ & $\sqrt{ }$ \\
\hline 10. Manuscript Writing & $\sqrt{ }$ & $\sqrt{ }$ & \\
\hline 11. Other (please specify which) & & & \\
\hline
\end{tabular}

